\title{
Dynamics of Revenues of Enterprises in Foreign Ownership at Russian Automotive Industry*
}

\author{
Cluster analysis in software Statistics
}

\author{
Vladislav Spitsin \\ Department of Management, Department of Economics \\ Tomsk Polytechnic University, Tomsk State University of \\ Control Systems and Radioelectronics \\ Tomsk, Russia \\ Spitsin_vv@mail.ru \\ Aleksandr Mikhalchuk \\ Department of Higher Mathematics \\ Tomsk Polytechnic University \\ Tomsk, Russia \\ aamih@tpu.ru
}

\author{
Andrey Trifonov \\ Department of Higher Mathematics \\ Tomsk Polytechnic University \\ Tomsk, Russia \\ Ilya Gumennikov \\ Department of Economics \\ Tomsk Polytechnic University \\ Tomsk, Russia \\ Anastasia Bulykina \\ Tomsk Polytechnic University \\ Tomsk, Russia
}

\begin{abstract}
This paper investigates the dynamics of revenue of foreign-owned enterprises in the automotive industry of Russia. Research period is 2011-2015. We propose and test the method of estimating the time series of data in the coordinates "staticsdynamics-sustainability", and use the method of cluster analysis of the obtained indices. Analysis showed that most of the largest foreign-owned enterprises were experiencing problems with the revenue growth in the period 2011-2015, in contrast to smaller enterprises. We found only one cluster, which is characterized by high rates of growth and sustainability. As a rule, high growth means medium stability or low stability. Many enterprises of Asian countries (Japan, South Korea) were identified among the growth leaders in the automotive industry of Russia.
\end{abstract}

Keywords - foreign-owned enterprises, foreign direct investment (FDI), revenue, dynamics, sustainability, estimation technique, cluster analysis

\section{INTRODUCTION}

The automobile industry is one of the most important branches in the economy of any country. It is characterized by a sufficiently high employment, science intensity and innovative results. This paper investigates development trends of the automotive industry in Russia by forms of ownership. This problem is relevant for Russia in conditions of allowing foreign and joint enterprises to operate in the Russian market and create favorable conditions for them, which equalize them with domestic producers. During the analysis of commercial enterprises, scientists usually distinguish three basic forms of ownership for enterprises: Russian (RO), joint (JO) and foreign (FO). In this paper, we focus on the study of enterprises in FO.

*The research is conducted with financial support from Russian Foundation for Basic Research (RFBR) in the frames of scientific and research project of RFBR named "Dynamic modeling of Russian, foreign and joint industrial enterprises development in situation of economic sanctions," project №. 17-06-00584(a).
The problem of the creation and development of enterprises in foreign and joint property is being actively studied by foreign scientists. Scientists Anwar and Sun [1]; You and Solomon [2]; Chayawisan [3]; Szkorupová [4] examine the impact of foreign direct investment (FDI) on the structure of capital and investment in domestic firms and their economic growth by forms of ownership. Such researchers as Dachs and Peters [5], Chen [6] and others [7-9] mark that FDI affects human capital of staff, labor productivity and salary at foreign and domestic enterprises. They also notice the significant role of foreign firms in innovation import in the national manufacturing $[8,9]$. In these articles it is noted that enterprises in FO and JO have certain advantages over domestic enterprises and create problems for the development of the latter in stable economic conditions.

A comprehensive analysis of the development of the automotive industry in Russia since the 1990s, as well as measures of state policy in this sphere, has been made by $\mathrm{N}$. Baronina [10] and Yu. Kurganov [11]. According to these studies, after the adoption of the legislation on industrial assembly in 2005, the processes of intensive establishment of enterprises in FO and JO began in Russia. The crisis of 20082009 has reduced the intensity of foreign investment. A new stage in the growth of enterprises in FO and JO occurred during the post-crisis period 2011-2012. By the production value, they became comparable with the enterprises in RO. At the same period there was a toughening of the regime of industrial assembly of cars and the Russian government began to conclude agreements on the assembly of automotive components in Russia [11]. Since 2013, the decline in car sales has been recorded, which is continuing in 2014 and is increasing in 2015. 
The aim this paper is to study the dynamics of revenue for enterprises in FO in the coordinates of "statics-dynamicssustainability" for the period 2011-2015. Enterprises in FO have found themselves in difficult conditions. The growth of 2011-2012 was replaced by a fall in demand and a fall in the ruble exchange rate. The latter factor had a negative impact on enterprises in FO with a low level of production localization in Russia. We also note the economic sanctions imposed by the United States, European and some Asian countries against Russia. In this paper, it is planned to investigate the reaction of enterprises in $\mathrm{FO}$ on these negative factors.

\section{Research Methodology}

The objects of research are enterprises in $\mathrm{FO}$ at the Russian automotive industry. The research period is 20112015. The data source is the SPARK database [12]. The analyzed sample comprised 51 enterprises in FO. The criterion for selecting enterprises is that they receive at least 100 million rubles of revenue annually during the period 20112015. Thus, large and stable enterprises were selected. Newly created or liquidated enterprises were excluded from the study.

The analysis technique consists of two stages.

1. Calculation the characteristics of the statics, dynamics and sustainability for each enterprise, which describe the time series of its revenue in 2011-2015.

Theoretical and practical aspects of the analysis of dynamics and sustainability of indicators are considered in papers $[13,14,15,16]$. In this study, the time trends of the revenue indicator of each enterprise are analyzed in the coordinates: "statics - dynamics - sustainability" according to the methodology proposed by V. Spitsin [17].

Statics (Yst) is characterized by a decimal logarithm of the average value of the indicator for the period:

$$
Y_{s t}=\log _{10}\left(\frac{\sum Y_{i}}{n}\right)=\log _{10} \bar{Y}
$$

where: Yi - actual values of the indicator for i year (2011, 2012, 2013, 2014, 2015);

$\mathrm{n}$ - the number of years analyzed.

Applying the logarithm is due to a strong spread in revenue between large and small enterprises. The logarithm of the average value of the indicator will allow to reduce this spread and to conduct clustering.

Dynamics and sustainability are calculated relative to the linear trend of the indicator for the period. Dynamics (Yd) corresponds to the coefficient of the variable in the linear trend, normalized to the module of the average value of the indicator for the period:

$$
\widetilde{Y_{l}}=a+b * X i
$$

where: $\mathrm{a}, \mathrm{b}$ - parameters of the linear trend equation;
$\mathrm{Xi}$ - variable determined by the years of the study period; in the case when the years $(\mathrm{Xi})$ are symmetric by zero $(-2 ;-1$; $0 ; 1 ; 2)$, the parameter a will be equal to $Y^{-}$;

$\mathrm{Yi}$ - the forecast values of the indicator for i year;

$$
Y d=\frac{b}{|\bar{Y}|}
$$

The value (Yd) can be positive, which means the growth of the indicator for the period under study according to the linear trend equation, and negative, which characterizes the decline of the indicator.

Sustainability (Ysust) is considered as the average annual deviation of the actual values of the indicator from the predicted values by linear trend, normalized to the module of the average value of the indicator:

$$
Y_{\text {sust }}=\frac{\sum\left|Y i-\widetilde{Y_{l}}\right|}{n *|\bar{Y}|}
$$

The calculated value Yust is always positive. The smaller it, the smaller the deviation from the linear trend. Further, when standardizing, we will flip it by zero and larger values Ysust* will correspond to a higher stability.

The proposed approach with the normalization of growth and deviations by the module of the average values of the indicator allows comparisons between different sizes of enterprises. We apply the module because the average values of separate indicators for some enterprises may be negative.

2. Clustering of enterprises in the coordinates "staticsdynamics- sustainability" and analysis of obtained clusters.

We perform cluster analysis according [18] and used software product "Statistics" for calculations. Clustering is based on the numerical characteristics Yst, Yd, Ysust* of the revenue. These characteristics are standardized. The clustering method is the joining (tree clustering) and the k-means method. Based on clustering, groups (clusters) of enterprises with similar values of the numerical characteristics Yst, Yd, Ysust* are formed. To estimate the numerical characteristics of Yst, Yd, Ysust* of each cluster, we apply the scale according to Table I.

TABLE I. COLOR LEVELS OF CLUSTER DIFFERENCES IN A STANDARDIZED DATA

\begin{tabular}{|l|l|l|}
\hline $\begin{array}{c}\text { Value of standardized } \\
\text { Yst, Yd, Ysust* }\end{array}$ & \multicolumn{1}{|c|}{$\begin{array}{c}\text { Cluster } \\
\text { estimation }\end{array}$} & \multicolumn{1}{c|}{ Color } \\
\hline $1,5<$ & Leader & Green \\
\hline$(0,5 ; 1,5)$ & Above average & Light green \\
\hline$(-0,5 ; 0,5)$ & Average & Yellow \\
\hline$(-1,5 ;-0,5)$ & Below the average & Orange \\
\hline$<-1,5$ & Outsider & Red \\
\hline
\end{tabular}

The graphs for the time series of revenue in 2011-2015 are constructed for the obtained clusters. 


\section{RESUlTS OF DEA AND Clustering ANALYSIS}

1. Clustering of enterprises in FO in the coordinates "statics-dynamics-stability" of revenue.

The consolidation of enterprises into clusters was carried out according to the constructed dendrogram (Fig. 1).

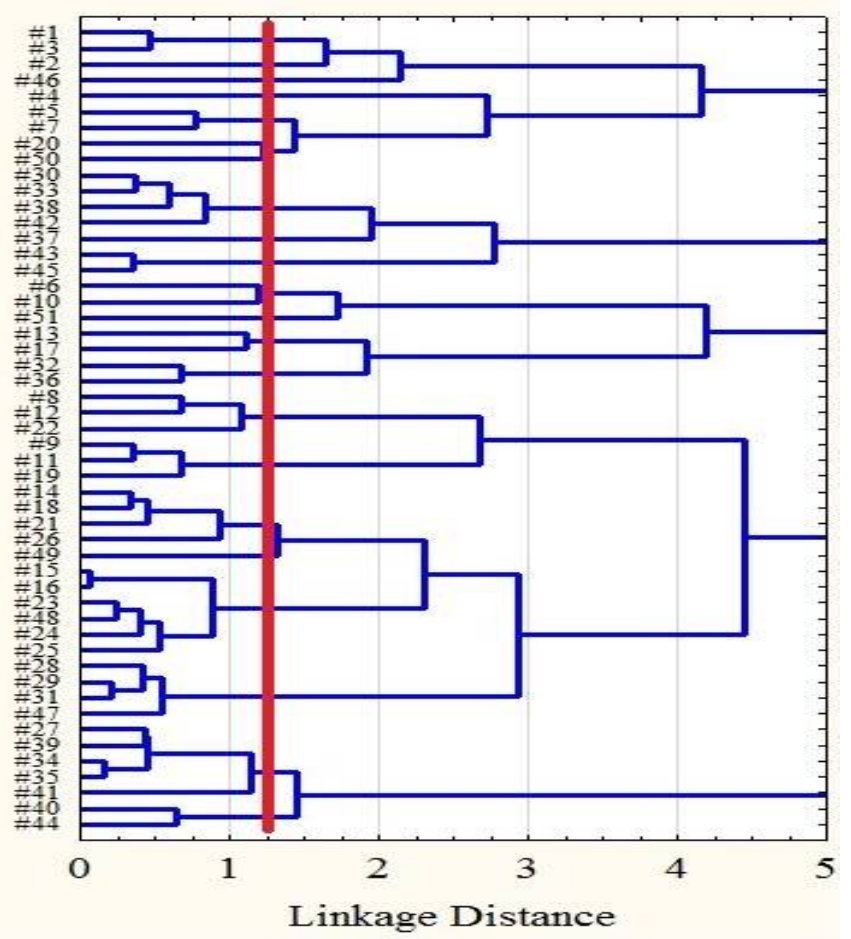

Fig. 1. Tree Diagram for 51 enterprises in FO

According constructed dendrogram, 51 enterprises in FO were divided into 20 clusters (Figure 2, Table II).

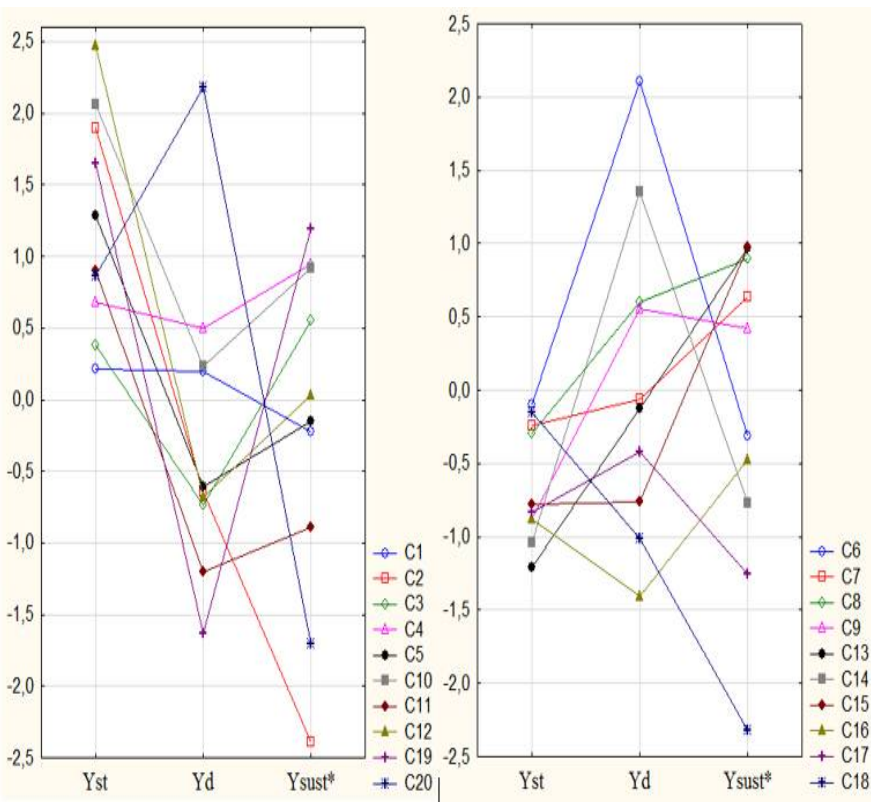

Fig. 2. Clustering Enterprises in FO by Their Standardized Coordinates Yst, Yd, Ysust* of Revenue
TABLE II. DISTRIBUTION OF ENTERPRISES IN CLUSTERS BY THEIR STANDARDIZED COORDINATES YST, YD, YSUST*

\begin{tabular}{|c|c|c|c|c|}
\hline $\begin{array}{c}\text { Enterprises } \\
\end{array}$ & Yst & Yd & Ysust* & $\mathrm{C}^{\mathrm{a}}$ \\
\hline Volkswagen GROUP RUS, LTD. & 2,64 & $-0,75$ & 0,19 & 12 \\
\hline XMMP, Open Company & 2,06 & 0,23 & 0,92 & 10 \\
\hline $\begin{array}{l}\text { NISSAN MANUFACTURING RUS, } \\
\text { LLC }\end{array}$ & 2,31 & $-0,60$ & $-0,12$ & 12 \\
\hline FORD SOLLERS HOLDING, LLC & 1,90 & $-0,64$ & $-2,39$ & 2 \\
\hline PSMA RUS, LLC & 1,47 & $-0,55$ & 0,18 & 5 \\
\hline MITSUBISHI MOTORS RUS, LLC & 1,18 & 2,26 & $-1,31$ & 20 \\
\hline DK RUS, LLC & 1,09 & $-0,66$ & $-0,48$ & 5 \\
\hline PITERFORM, LLC & 0,59 & 0,39 & 0,21 & 1 \\
\hline LIR, LTD. & 0,59 & $-0,49$ & 0,67 & 3 \\
\hline ISUZU RUS, JSC & 0,19 & 2,87 & $-1,55$ & 20 \\
\hline BENTELER AUTOMOTIVE, LTD. & 0,50 & $-0,81$ & 0,55 & 3 \\
\hline $\begin{array}{l}\text { GESTAMP-SEVERSTAL- } \\
\text { KALUGA, LLC }\end{array}$ & 0,38 & 0,07 & $-0,35$ & 1 \\
\hline TOYOTA BOSHOKU, LLC & $-0,06$ & 2,36 & 0,17 & 6 \\
\hline LEONI RUS, LLC & $-0,01$ & 0,79 & 0,74 & 8 \\
\hline DONHI RUS, LLC & 0,03 & $-0,00$ & 0,7 & 7 \\
\hline DVR, OOO & 0,02 & $-0,01$ & 0,77 & 7 \\
\hline EESR, LLC & $-0,13$ & 1,84 & $-0,8$ & 6 \\
\hline YAZAKI VOLGA, LLC & $-0,23$ & 0,59 & 0,57 & 8 \\
\hline $\begin{array}{ll}\text { GESTAMP } & \text { SEVERSTAL } \\
\text { Vsevolozhsk, LLC } & \\
\end{array}$ & 0,05 & $-0,92$ & 0,46 & 3 \\
\hline SCANIA-PITER, LLC & 0,35 & $-1,14$ & $-0,64$ & 11 \\
\hline FmiS, Inc. & $-0,31$ & 0,61 & 0,98 & 8 \\
\hline Johnson Matti Catalysts, LLC & $-0,33$ & 0,12 & $-0,54$ & 1 \\
\hline SV RUS, LLC & $-0,42$ & $-0,03$ & 0,6 & 7 \\
\hline SCHRZH, LTD & $-0,51$ & 0,13 & 0,79 & 7 \\
\hline Bozal, Open Company & $-0,37$ & $-0,30$ & 0,32 & 7 \\
\hline TAV, LLC & $-0,64$ & 0,41 & 1,3 & 8 \\
\hline NOVTRAK, CJSC & $-0,61$ & $-0,50$ & 1,15 & 15 \\
\hline YAPP RUS, LLC & $-0,76$ & 0,58 & 0,17 & 9 \\
\hline REIDEL AUUTOMOTIV RUS, LLC & $-0,78$ & 0,52 & 0,58 & 9 \\
\hline EABC, LLC & $-0,75$ & $-0,18$ & $-1,58$ & 17 \\
\hline MV KINGISEPP, LLC & $-0,84$ & 0,38 & 0,43 & 9 \\
\hline FOIT TURBO, LTD. & $-1,09$ & 1,47 & $-1,09$ & 14 \\
\hline KEYEYSI, LTD & $-1,01$ & $-0,26$ & $-1,33$ & 17 \\
\hline DAYDO METAL RUSS, LTD & $-0,79$ & $-0,75$ & 1,08 & 15 \\
\hline TI AY AUTOMOTIVE, LLC & $-0,85$ & $-0,78$ & 0,93 & 15 \\
\hline DINEKS RUSS, LTD & $-0,98$ & 1,23 & $-0,46$ & 14 \\
\hline NAME-M, JSC & $-0,15$ & $-1,01$ & $-2,32$ & 18 \\
\hline HP PELTSER RUS, LLC & $-0,91$ & $-0,34$ & $-0,95$ & 17 \\
\hline YAROSLAVSKY EMZ & $-0,95$ & $-0,67$ & 1,33 & 15 \\
\hline $\begin{array}{l}\text { AUUTOCOMPONENT } \\
\text { ENGINEERING-2, LTD. }\end{array}$ & $-1,16$ & 0,06 & 0,7 & 13 \\
\hline Edent Sitting, LLC & $-0,68$ & $-1,11$ & 0,42 & 15 \\
\hline MILLER VOSTOK, LLC & $-0,68$ & $-0,88$ & $-1,14$ & 17 \\
\hline SIMOS-ZKS, LLC & $-0,77$ & $-1,47$ & $-0,61$ & 16 \\
\hline Bozal-AVTOFLEKS, LLC & $-1,26$ & $-0,31$ & 1,23 & 13 \\
\hline IPV, LLC & $-0,98$ & $-1,35$ & $-0,34$ & 16 \\
\hline FORD MOTOR COMPANY CJSC & 1,65 & $-1,63$ & 1,19 & 19 \\
\hline ANVIS ENG, LLC & $-1,13$ & 0,74 & 0,52 & 9 \\
\hline AD PLASTIC, JSC & $-0,23$ & $-0,18$ & 0,62 & 7 \\
\hline MOBIS MODULE CIS, LLC & 0,68 & 0,49 & 0,94 & 4 \\
\hline JI EM AUTO, LLC & 1,46 & $-1,25$ & $-1,14$ & 11 \\
\hline FS ELABUGA, LLC & 1,21 & 1,41 & $-2,24$ & 20 \\
\hline
\end{tabular}

2. Evaluation of the numerical characteristics of "staticsdynamics-stability" for the clusters obtained.

Estimates of the numerical characteristics Yst, Yd, Ysust* for each cluster are presented in Fig 3. In Fig 3 we apply the color levels according to Table I and clusters are arranged in descending order of standardized Yst which corresponds to the decrease in average revenue. 


\begin{tabular}{|c|c|c|c|c|}
\hline Cluster & N & Yst & Yd & Ysust $^{*}$ \\
\hline C12 & 2 & 2,473 & $-0,677$ & 0,034 \\
\hline C10 & 1 & 2,057 & 0,231 & 0,919 \\
\hline C2 & 1 & 1,899 & $-0,645$ & $-2,393$ \\
\hline C19 & 1 & 1,652 & $-1,627$ & 1,19 \\
\hline C5 & 2 & 1,280 & $-0,606$ & $-0,154$ \\
\hline C11 & 2 & 0,904 & $-1,198$ & $-0,889$ \\
\hline C20 & 3 & 0,862 & 2,181 & $-1,7$ \\
\hline C4 & 1 & 0,685 & 0,494 & 0,944 \\
\hline C3 & 3 & 0,381 & $-0,737$ & 0,558 \\
\hline C1 & 3 & 0,215 & 0,194 & $-0,227$ \\
\hline C6 & 2 & $-0,096$ & 2,103 & $-0,312$ \\
\hline C18 & 1 & $-0,152$ & $-1,012$ & $-2,318$ \\
\hline C7 & 6 & $-0,246$ & $-0,066$ & 0,633 \\
\hline C8 & 4 & $-0,299$ & 0,601 & 0,895 \\
\hline C15 & 5 & $-0,776$ & $-0,762$ & 0,981 \\
\hline C17 & 4 & $-0,836$ & $-0,417$ & $-1,25$ \\
\hline C16 & 2 & $-0,874$ & $-1,408$ & $-0,477$ \\
\hline C9 & 4 & $-0,877$ & 0,557 & 0,425 \\
\hline C14 & 2 & $-1,035$ & 1,353 & $-0,775$ \\
\hline C13 & 2 & $-1,210$ & $-0,124$ & 0,966 \\
\hline
\end{tabular}

$\mathrm{N}$ - number of enterprises included in the cluster.

Fig. 3. Cluster Average Values And Their Estimation In Color Levels

F-test shows that the differences between the average values of clusters in their entirety are highly significant (at the level of $\mathrm{pF}<0,0005)$ for each indicator. The smallness of the clusters samples assumes control of the results rank KruskalWallis test, which confirms the findings of F-test in a bit milder form ( $\mathrm{pK}-\mathrm{W}<0,0005$ for $\mathrm{Yst}$ and $\mathrm{Yd}$; $\mathrm{pK}-\mathrm{W} \approx 0,0006$ for Ysust*).

By the variable Yst cluster leader $\mathrm{C} 12$ insignificant $(\mathrm{pF}>$ $0,10)$ from $\mathrm{C} 2$ and $\mathrm{C} 10$, statistically significant $(0,005<\mathrm{pF} \approx$ $0,033<0,05)$ from $\mathrm{C} 19$ and highly significant $(\mathrm{pF}<0,0005)$ from all others. C5 insignificant $(\mathrm{p}>0,10)$ differs from $\mathrm{C} 11$ and $\mathrm{C} 13$ weakly significant differs $(0,05<\mathrm{pF} \approx 0,09<0,10$; $0,05<\mathrm{pK}-\mathrm{W} \approx 0,053<0,10$ ) from $\mathrm{C} 15$. By variable $\mathrm{Yd}$ cluster leader $\mathrm{C} 20$ differs insignificant $(\mathrm{pF}>0,10)$ from $\mathrm{C} 6$, strongly significant $(0,0005<\mathrm{pF} \approx 0,002<0,005)$ from $\mathrm{C} 14$ and highly significant from all others. C5 statistically significant $(0,005<$ $\mathrm{pF} \approx 0,036<0,05)$ differs from $\mathrm{C} 11$ and C13 is statistically significant $(0,005<\mathrm{pF} \approx 0,008<0,05)$ different from $\mathrm{C} 15$. By variable Ysust* cluster leader $\mathrm{C} 2$ differs insignificant $(\mathrm{pF}>$ $0,10)$ from $\mathrm{C} 18$, weakly significant $(0,05<\mathrm{pF} \approx 0,07<0,10)$ from $\mathrm{C} 20$, strongly significant $(0,0005<\mathrm{pF}<0,005)$ from $\mathrm{C} 11, \mathrm{C} 17$ and highly significantly from all others. C5 statistically significant $(0,005<\mathrm{pF} \approx 0,030<0,05)$ differs from $\mathrm{C} 11$ and $\mathrm{C} 13$ is insignificant $(\mathrm{pF}>0,10)$ different from C15.

Clusters C12 (Volkswagen Group RUS, LTD; Nissan Manufacturing RUS, LLC) and C10 (XMMP, Open Company) are the largest by average value of revenue. The remaining clusters and enterprises are far behind. Calculations show serious problems with the "dynamics" index (Yd) for the first 6 clusters (i.e. for clusters with the maximum values of average revenue). Only one of the nine enterprises (cluster C10, XMMP Open Company) included in these clusters has the "dynamics" rating (Yd) at the average level (yellow color). The rest are below average and there is one outsider. Such problems are not observed in clusters with smaller volumes of average revenue. There are leaders by "dynamics" rating (Yd) among them (clusters C6), and some of these clusters show growth above the average (clusters C8, C9, C14).

Thus, the largest enterprises in FO in the Russian automotive industry experienced serious problems with revenue growth in 2011-2015, in contrast to smaller enterprises.

We have not identified similar differences in the sustainability index (Ysust*). We found only one cluster C8, which is characterized by high rates of growth $(\mathrm{Yd})$ and stability (Ysust*). As a rule, high growth means medium stability (cluster C6) or low stability (cluster C20).

Dynamics of revenue (R) in absolute values in 2011-2015 for the formed clusters is shown in Fig. 4.
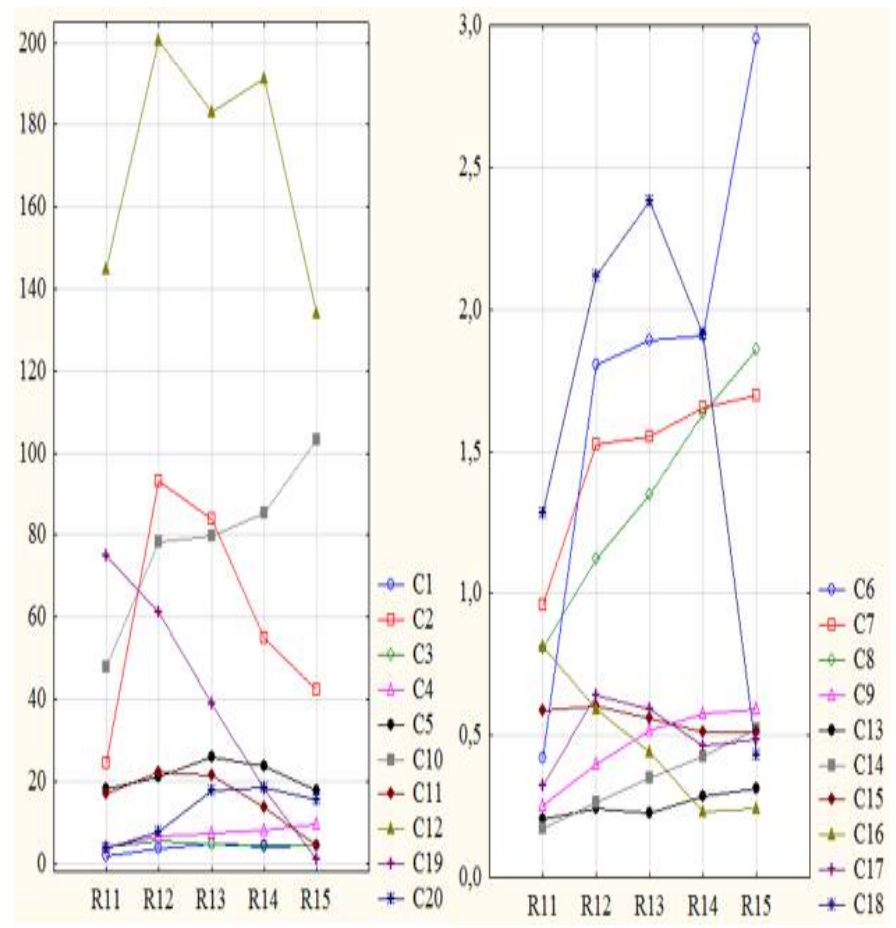

Fig. 4. Dynamics Of Revenue For The Clusters Of Enterprises In FO, Billion Rubles.

Fig. 4 clearly shows the dynamics of clusters and their enterprises. We observe problems with revenue growth for most of the clusters with largest enterprises. Only clusters C10 and $\mathrm{C} 20$ show the growth of revenue. Conversely, there are several clusters among small enterprises (clusters C6, C8, C9, $\mathrm{C} 14$ ), which are demonstrating high growth of revenue. We have revealed that among the growing clusters there are many enterprises of Asian countries (Japan, South Korea). 


\section{CONCLUSIONS}

The conducted analysis allows us to make the following conclusions.

1. We have tested the approach to the estimation of time series in the coordinates "statics-dynamics-stability". This approach is applied to the analysis of time series of revenues for enterprises in FO at the automotive industry in Russia.

2. The grouping of enterprises into clusters is performed and estimates of the "statics-dynamics-sustainability" of revenue for each cluster are given based on statistical methods.

3. Analysis showed that most of the largest enterprises in FO experienced problems with revenue growth in the period 2011-2015, in contrast to smaller enterprises.

4. Leaders in revenue growth rarely demonstrated a steady increase in this indicator. As a rule, high growth lasted only 12 years of the research period and meant medium stability or low stability.

5. Among the growth leaders, many enterprises of Asian countries (Japan, South Korea) were identified.

The study showed problems with growth in the group of large enterprises and, on the contrary, the presence of growth leaders among small enterprises. However, leaders in revenue growth rarely demonstrated a steady increase in this indicator.

We can assume an increase in the competition of producers, which will hinder the growth of prices. The interest of Asian companies to the Russian car market has also been revealed in the conditions of economic sanctions, which should be considered in the state regulation of this branch of the economy.

\section{REFERENCES}

[1] S. Anwar, and S.Sun, "Can the presence of foreign investment affect the capital structure of domestic firms?", Journal of Corporate Finance, vol. 30, pp. 32-43, 2015.

[2] K. You, and O.H. Solomon, "China's outward foreign direct investment and domestic investment: An industrial level analysis," China Economic Review, № 34, pp. 249-260, 2015.

[3] N. Chayawisan, "Interaction between domestic and foreign direct investment in Thailand. British Journal of Economics," Management and Trade, № 9(2), pp. 1-6, 2015.

[4] Z. Szkorupová, "Relationship between Foreign direct investment and domestic investment in selected countries of central and Eastern Europe”, Procedia Economics and Finance, № 23, pp. 1017-1022, 2015.

[5] B. Dachs, and B. Peters, "Innovation, employment growth, and foreign ownership of firms: A European perspective”, Research Policy, №43, pp. 214-232, 2014.

[6] W. Chen, "The effect of investor origin on firm performance: Domestic and foreign direct investment in the United States," J. of International Economics, № 83, is. 2, pp. 219-228, March 2011.

[7] Z. Chen, Y. Ge, and H. Lai, "Foreign Direct Investment and Wage Inequality: Evidence from China," World Development, vol. 39, № 8, pp. 1322-1332, Aug. 2011. doi:10.1016/j.worlddev.2010.12.006

[8] S. Girma, Y. Gong, and H. Görg, "What Determines Innovation Activity in Chinese State-owned Enterprises? The Role of Foreign Direct Investment," World Development, vol. 37, № 4, pp. 866-873, Apr. 2009. doi:10.1016/j.worlddev.2008.07.017
[9] Y. Murakami, "Technology spillover from foreign-owned firms in Japanese manufacturing industry," Journal of Asian Economics, vol. 18 , № 2, pp. 284-293, Apr. 2007. doi:10.1016/j.asieco.2007.02.002

[10] Yu. Baronina, "Foreign Investment into Russian Automotive Industry," Mirovaya ekonomika i mezhdunarodnye otnosheniya, v. 60, № 6, pp. 61-69, 2016. DOI: 10.20542/0131-2227-2016-60-6-61-69.

[11] Yu. A. Kurganov, "Current trends and conditions of production cooperation development in Russia's automotive industry," Rossiyskiy vneshneekonomicheskiy vestnik, № 10, pp. 96-103, 2015. URL: http://www.rfej.ru/rvv/id/A00384BB9.

[12] Information resource SPARK, Russia, 2017. URL: http://www.sparkinterfax.ru/

[13] E.A. Tretyakova, and M. Yu. Osipova, "Combination of static and dynamic approaches to assessing sustainable development of regional socio-economic systems," Bulletin of Perm University. Series: Economy, № 2(29), pp. 79-92, 2016.

[14] V. Spitsin, A. Mikhalchuk, L. Spitsina, E. Akerman, T. Nataliya, A. Semes, and D. Novoseltseva, "Comparative Analysis of Salary, Labor Intensity and Payroll-Output Ratio of Foreign and Domestic Firms: Case Russian Vehicle Industry," Proceedings of the 2015 International Conference on Education Reform and Modern Management, 2015. doi:10.2991/ermm-15.2015.97

[15] I. S. Antonova, E. A. Pchelintsev, and D. D. Vavilov, "Dynamic Approach for Diversification Effectiveness Evaluation of Berezovsky Company Town," Advances in Computer Science Research, Vol. 51 : Information Technologies in Science, Management, Social Sphere and Medicine (ITSMSSM 2016), pp. 328-331, 2016. URL: http://dx.doi.org/10.2991/itsmssm-16.2016.8

[16] I. S. Antonova, O. A. Negodina, K. S. Koptelova, L. Y. Spitsina, S. N. Popova, and D. D. Vavilov, "Investment Attractiveness of Closed-end Real Estate Investment Funds in Russia: Factor Score Evaluation," Proceedings of the 2016 International Conference on Education, Management, Computer and Society, 2016.

[17] V.V. Spitsin, "Methodological approach to assessing the effectiveness of development of complex socio-economic systems," Economics: yesterday, today, tomorrow, iss. 7, no. 4A, pp. 25-32, 2017.

[18] T. Hill, P. Lewicki, "Statistics: Methods and Applications," StatSoft, Tulsa, OK, 2007. 